\title{
Collaborating, Competing, Co-working, Coalescing: Artists, Freelancers and Social Entrepreneurs as the 'New Subjects' of the Creative Economy
}

\author{
Alessandro Gandini*, Carolina Bandinelli* \\ and Alberto Cossu ${ }^{\dagger}$ \\ * King's College, London \\ †University of Milan
}

More than a decade after the enthusiastic call for the rise of a 'creative class' (Florida, 2002), the conditions of today's creative economy appear to be quite different from the expectations that accompanied its acclaimed surge as a propeller of economic development in the late 1990s and early 2000s. The frenzy around creativity that has characterised cultural economies as a whole since then has evolved into a context that is now largely animated by a casualisation and entrepreneurialisation of work, with project-based employment rising to an unprecedented scale (McRobbie, 2015).

How to cite this book chapter:

Gandini, A., Bandinelli, C. and Cossu, A. 2017. Collaborating, Competing, Co-working, Coalescing: Artists, Freelancers and Social Entrepreneurs as the 'New Subjects' of the Creative Economy. In: Graham, J. and Gandini, A. (eds.). Collaborative Production in the Creative Industries. Pp. 15-32. London: University of Westminster Press. DOI: https://doi.org/10.16997/book4.b. License: CC-BY-NC-ND 4.0 
Within this context, the recent popularisation of a 'hip' discourse around innovation, collaboration and sharing, particularly across those once labelled as 'creative cities' (Landry, 2000), has involved many working subjects. Among them, three social actors seem to be particularly involved: freelancers, social entrepreneurs and artists. Freelancers have been repeatedly advocated as trailblazers of an on-demand economy based on distributed forms of work (The Economist, 2015); similarly, social entrepreneurs have risen to prominence for epitomising the attempt to pursue more 'ethical' forms of business in and for society after the economic crisis (Bandinelli and Arvidsson, 2013); whilst artists are reclaiming a newly central role in their experimentation with new forms of critique against late capitalist modes of accumulation stemming from the digital realm (Sholette, 2011). These characters, in their own specificities, provide us with three peculiar forms of subjectivity worthy of a closer look, as too the fashionable but also quite contradictory traits that characterise their role in the present conjuncture.

This chapter is concerned with offering an understanding of the main traits that characterise the subjectivity of these social actors, and assess their emergence and significance. Building on individual ethnographic fieldwork conducted in various contexts between 2011-2014, we offer an ex post reflection that draws from each author's empirical research to provide a better understanding of the role these subjects play in the meeting of collaboration and creativity. These, we will argue, represent - each with its own peculiar features an accurate illustration of the process of reshaping the creative economy in the shift towards collaboration and sharing - a shift one encounters in the confluence of emergent 'alternative' economic perspectives in the aftermath of the financial crisis and the rise of forms of economic valorisation that are increasingly rooted in the social (Arvidsson and Peitersen, 2013).

Within this scenario, freelancers, social entrepreneurs and artists have intervened in the social fabric by operating in peculiar, but somewhat analogous ways, blending collaboration, entrepreneurship and creative practice in an original manner. Each from their own standpoint, they now reclaim a central role in an urban collaborative scene that they commonly consider the space for the enactment of their creative, (self)entrepreneurial endeavours. Their subjectivity, as we are about to observe, is similarly characterised by a political attitude towards change and an ideological disposition to 'newness', that is made explicit in the attempt to combine economic with what may be seen as forms of 'aest-ethical' action - and is nonetheless frustrated in the capacity to coalesce as a collective subject within and beyond the fragmented scene they inhabit. By operating in a milieu largely determined by a market economy, yet nonetheless experimenting with forms of commons-based peer production, we argue that freelancers, social entrepreneurs and artists are manifestations, in their own peculiar ways, of that process of 're-embeddedness' of the economic into the social (Pais and Provasi, 2015) that seems to characterise the current socio-economic conjuncture. 


\section{Setting up the context: the creative economy in the age of austerity}

In Be Creative, Angela McRobbie (2015) gives an account of the evolution of the creative economy on a global scale in the last decade, from post-New Labour Britain to the post-crisis scenario. McRobbie argues that the creative economy represents the political packaging of a neoliberal vision of work founded on entrepreneurialism and organised on project work and flexible employment relations. Today, she maintains, a set of varied phenomena characterise this context, from social entrepreneurship to hipsterism, all marked by the realisation of the artist as economic pioneer she had earlier predicted (McRobbie, 2002).

The most recent employment figures available on the creative sector in the UK seem to support this interpretation. Similar to what happened with the DCMS reports in 1999 and 2002, recent government-issued data on the creative economy convey the picture of a growing economic scene where a variety of jobs are up for grabs in a job market that includes a broad range of industries, from architecture to marketing, for a 'scene' that is depicted as being constituted by highly qualified workers, mostly male and white (DMCS, 2015). However, what these representations do not adequately account for or explain is what kind of jobs are those at stake, whether secure or precarious, economically satisfying or scarcely paid, and especially what kind of 'quality' intended as the sociology of work (Kalleberg, 2011; Hesmondhalgh and Baker, 2011) characterises it. This is an important issue, considering that the creative labour market has largely been described as one made of 'lousy and lovely' jobs (Goos and Manning, 2007; Ross, 2009) whereby, beyond high level skill requirements, it is the capacity to network and brand one's passion and talent, often in exchange for scarce or no economic remuneration, that makes the real difference (Gandini, 2016b; Arvidsson et al., 2010; McKinlay and Smith, 2009).

Recent data confirm how creative workers today have a higher-than-average likelihood of being self-employed or working on a freelance basis, as a result of an environment that induces them into developing independent and resilient subjectivities (Prospects, 2015). An eminently project-based structure characterises this highly-skilled labour market, where a mere 1 per cent of the creative workforce gets permanent jobs through an apprenticeship route, and 48 per cent of workers engage in unpaid work at some point in their career. Yet, the rate of diffusion of freelance-based employment varies consistently from one industry to another, from 9 per cent in VFX (Visual Effects) to 90 per cent in film and television (CreativeSkillset, 2015). What is common to all these sectors is that job seeking practices rely ever more on the capacity of workers to navigate across personal contact networks, something that has historically characterised creative work (Gandini, 2016b; Blair, 2001).

Put differently, despite being culturally constructed around the idea of a creative class of workers who actively valorise their talent and skills (Florida, 2002), 
the actual nature of this labour market in practical terms is exemplary of an eminently neoliberal, strategically-pursued logic of flexibilisation of work relations and entrepreneurialisation of the workforce (Bonini and Gandini, 2016; Christopherson 2008; Neilson and Rossiter, 2008). The rapid diffusion of social media has further amplified the more controversial aspects of this condition. While allowing workers to showcase their skills, develop a personal brand and network more efficiently, at the same time social media enabled a refinement of the managerial processes of flexibilisation, with technological infrastructure affording remote working and social interaction in new and unprecedented ways (Gandini, 2016b).

Nonetheless, within such a complicated scenario, we are witnessing today a rejuvenated version of an already hyper-enthusiast discourse, that is rooted within the premises and promises of a 'sharing economy' that magnifies the opportunity for workers to collaborate with others across creative, (self)entrepreneurial endeavours (Botsman and Rogers, 2010). The rise of such discourse calls for a necessity to put into question the dialectical relationship between the economic and the social within this context, and to investigate what features this nexis possesses insofar as collaboration and sharing become relational dispositifs of power (Foucault, 2008; Lazzarato, 2009) that serve to purposes of socially-conceived value production (Arvidsson and Peitersen, 2013).

Within this framework, three anomalous creative subjects have come to stand out. We say anomalous here as a result of their comprehensively multidimensioned subjective dynamic, that we are about to observe in detail. Freelancers, as noted, are vital to today's vision of the creative economy; it may be said, as Barley and Kunda (2006) envisaged, that the diffusion of managerial visions of knowledge work built around distributed models of work was inevitably destined to put freelancers in a prominent position. Today, this idea has even led The Economist (2015) to advocate the surge of an 'on-demand economy' made of 'workers on tap' who offer contract-based work to various service providers, mainly digital-based ones, at various levels. Collaborative practice is a natural component of the professional subjectivity for freelancers, as a result of the well-known emphasis on networking that characterises their working practice, and blends with the ambivalent social and economic nature of their action, which stands at the interface of entrepreneurialism and precarity (Arvidsson et al., 2016; Gandini, 2016b). Similarly, social entrepreneurship has been a recently growing phenomenon involving a variety of actors across a range of fields including politics, civic society, business and academia. According to a 2013 survey published by Social Enterprise UK, it is estimated that 70,000 social enterprises currently exist in the UK, employing around a million people. The sector's contribution to the economy has been valued at over $£ 24$ billion (Social Enterprise UK, 2013).

Lastly, the position of artists in this renewed encounter of the economic and the social is also of peculiar interest. Alongside other cultural workers, artists today are increasingly engaged in the reclamation of social and political space, 
broadly defined. As demonstrated by a series of recent events, artists participate in broad social movements (such as Occupy and Gezi Park) or create movements of their own (such as the Network of Occupied Theaters in Italy and Greece). They protest against the structures and dynamics of the art world (e.g. Liberate Tate), experiment with alternative economic models and currencies (e.g. Macao and D-CENT), and host or co-produce public art at a time when the budget for culture and independent projects in this field is generally shrinking (Faccioli et al., 2014). They undertake social research, partner up with institutions and various entities, support neighbourhoods and sometimes also fill the void left by nation states in social and cultural action that results from their neoliberal-driven disinterest in intervening in society unless this intervention is economically-oriented (which means turning a profit for the private sector).

Building on the ambivalent centrality of these subjects, we argue that the literature on creative work has so far been unable to fully account for the existence of a peculiarly strong dialectical relationship between the economic and the social, that is distinctive of the processes of subjectification that characterise creative, cultural and knowledge workers, and that is now coming to further prominence. Creative workers have long engaged in forms of collaborative work that enable them to explore the possibilities of a performative re-articulation of their social standing through creativity, and its re-signification into forms of economic action. Today, as a result of the current logics of creative work and the discursive regimes of collaboration and sharing deploying around them, their subjectivity finds new and multiple forms of expression that call for a closer observation.

Hence, in this chapter we read some of the most recent social forms of collaboration that characterise social actors in the creative economy as the manifestation of a greater process of re-embeddedness of the economic in society. The concept of a 're-embeddedness' of the economic in society draws on the work by sociologist Karl Polanyi and his analysis of the Great Transformation wrought by the Industrial Revolution ([1944] 2001). As Pais and Provasi (2015) have argued, today's rise of initiatives orientated around collaboration and sharing may be read, potentially, as a phenomenon that is able to completely re-embed economic relations within social ones, after a century characterised by a 'dis-embedding' of economic action from its eminently social resonance, favoured by the diffusion of hierarchies and markets as dominant organisational forms (Williamson, 1973).

In the following sections, using thick ethnographic description based on each author's field research, we will look more closely at the similarities and differences that characterise freelancers, social entrepreneurs and artists and how they come to prominence now as protagonists of the current social and economic transition. In so doing, we offer an account and a critical understanding of their subjectivities, to illustrate the main traits of the dialectical relationship between the economic and the social here argued, and to discuss the extent to which they incarnate a form of re-embeddedness of the economic into the 
social that is peculiar to the creative economy. In each section, we will question the extent to which the idea of collaboration produces, and is produced by, processes of subjectivisation that peculiarly characterise these social actors. Central questions are: what does collaboration mean for them? How does it stand in relation to the more economic aspects of their societal action? To what extent can we envisage the possibility that new forms of collective organisation or coalition can be experienced in this scenario? With this in hand, we will conclude by offering a reflection that takes these actors as exemplary subjects of such process of re-embeddedness of the economic into the social in the emergent collaborative economy of creativity - and further highlight the contradictions this entails, pondering on the extent to which these might turn out to be substantially unsolvable in the present socio-economic context.

\section{The market subjectivity of freelancers}

As anticipated, freelancers have long been at the heart of a vision that set independent workers as the protagonists of a shift towards decentralised and distributed work models in the rising economy of new media (Malone and Laubacher, 1998). Yet, the growth of distributed models of work has been accompanied by a concomitant rise in precarity and project-based work (McKinlay and Smith, 2009), which has rendered this vision very much a controversial one.

The insights provided here on freelancers build on a study of the network cultures and practices of freelance work in London and Milan, conducted in 2012-213 by one of the authors through an ethnographic framework, and consisting of 80 interviews (38 in London, 42 in Milan) with a variety of independent professionals working in various contexts in the creative and cultural industries - especially communication-based and digital media industries. Freelancers emerge in this study as a comprehensively young and highly-skilled workforce, well-educated and networking-obsessed in their professional disposition. Although their earnings would leave them unable to live in the urban centres of high-rent cities such as London and Milan, they are very much urban subjects who approach the city as the environment where their work may find appropriate recognition - insofar as this depends on the access to relevant professional networks (see Gandini, 2016b). The presence of such a trait is somewhat inevitable in a labour market built on a logic for which 'you are only good as your last job' (Blair, 2001), that is taken for granted by the same workers.

The forms of subjectification freelancers exhibit are deployed as a response to such a context - a response which, nevertheless, takes two distinct forms. A first one consists in the embodiment of entrepreneurialism as a discursive device and logic of action. This includes a conception of social media as a terrain for self-branding, and of freelancing as a professional condition whereby the practice of free labour represents a form of 'investment' with expectation of economic and reputational return (Gandini, 2016a). The 'other side' of this 
form of subjectivity is the existence of a condition of endemic professional uncertainty that many - although not all - respondents relate to instances of precariousness and exploitation. This showcases an ambivalent scenario, epitomised by the contrasting meaning that freelancers attach to the words 'competition' and 'collaboration'. In spite of the highly competitive work that freelance professionals experience, collaboration for them ostensibly outperforms competition, through a logic of action that is deeply economic as well as social given that the most important aspect a freelancer must look after is always, first and foremost, one's contacts and reputation within the professional network.

This is not to say, however, that freelance scenes are non-competitive environments - actually, the opposite is true. In fact, it may be argued that a freelancer's subjectivity is eminently a market-orientated one, insofar as one's market coincides with one's social sphere - the personal network of contacts and, in tandem, social relations represent the object of a process of marketisation that takes place with various degrees of ideological adherence. To some extent, this can be described as somewhat of analogous to the concept of illusio (Bourdieu, 1996) also described in this collection by Patel (2017), being a process akin to the gamification of social status that keeps together the logics of cultural work and the construction of one's expertise - in this case, however, an elaborately constructed social status, curated through the management of reputation via social networks.

This process seems to be deeply entrenched with the framing of a notion of collaboration as a discursive device that keeps together two opposing forms of subjectification in a comprehensively market-oriented subjectivity. For some, this consists in a discursive recoding of their ethos into a narrative of 'liberation' and release from the constraints of office work. For others, on the other hand, this fully reflects their condition of 'immaterial workers' (Lazzarato, 1996), characterised by exploitation, alienation, long hours of work and a need to comply with the anxiety over the unpredictability of work-related duties that completely redefine working times. Put differently, we may see the existence of a 'fracture' in the subjectivity of freelancers, that makes them a textbook example of the market-oriented side of the dialectical relationship between the economic and the social that is under discussion in this chapter.

This ambivalent positioning of the freelance subjectivity renders freelancers a comprehensively plural and heterogeneous set of subjects with limited political subjectivity, and - in addition - a frustrated potential to coalesce into a collective subject. The entrepreneurial aspects of freelance work are in fact often so strongly attractive that the option to coalesce against the precarious and exploitative side of this working condition fails to be perceived as such by freelancers themselves, and sometimes comes to be explicitly refused. The diffusion of co-working spaces evidences this aspect. Despite the existence of accounts that envisage a role for co-working spaces as places where a potential coalition and re-collectivisation of individualised working subjects can take place (de Peuter, 2014), within co-working spaces freelancers more typically work 
independently rather than collaboratively, and pursue socialisation mainly for entrepreneurial rather than communitarian purposes (Gandini, 2015). In short, freelancers are a hybrid social group whose subjectivity is at present very far from being capable of building a political collective consciousness around their professional condition. This is further supported by the widespread presence of freelancers in both the other categories of 'collaborative' creative workers considered here, starting with social entrepreneurs.

\section{The ethical subjectivity of social entrepreneurs}

To explore the subjectivity of social entrepreneurs, this section builds on qualitative, ethnographic fieldwork conducted by one of the authors at two branches of the most important global co-working franchise for social entrepreneurs in Westminster, London and Milan: Impact Hub (see Bandinelli, 2016). The research methodology involved participant observation, interviews, events ethnography and action research in the period November 2011 to March 2012 (London, Westminster) and April to June 2012 (Milan).

As in most ethnographies, the majority of the data comes from informal interaction between the researcher and the participants. In terms of demographics, the vast majority of the social entrepreneurs encountered in this research are white, well-educated men and women in their late twenties/early thirties. Many work in the knowledge and creative industries as freelancers or independent professionals on a contract-basis, or as entrepreneurs (mostly a one-person company). They usually have a background in disciplines across media and communication, consultancy, architecture and design, and work on projects in a variety of fields in the creative industries and beyond, such as consultancy, finance, technology and innovation. As a result, such a picture prevents us from seeing clearly the relationship of social entrepreneurs to a specific economic sector. In fact, it may be argued that what defines social entrepreneurs is a specific subjectivity characterised by a specific world vision that is marked by a certain set of beliefs. The core of the social entrepreneurial subjectivity is the belief that entrepreneurial means can be used effectively to pursue the common good, and improve the conditions of society. This goal is encapsulated in the widespread formula 'change the world', and represented by the trademark term coined by Ashoka (one of the largest organisation supporting social entrepreneurship): changemakerTM (Bandinelli and Arvidsson, 2013).

In spite of how hyperbolic and vague these expressions may be - indeed they leave unanswered a series of key questions about the nature of this 'change' they nonetheless signal the presence of a strong dimension concerning ethics. The term 'ethics', as we use it here, has two main connotations. The first one points to a very general notion of ethics, that is a system of values and action directed towards collective happiness (as summed up by the Aristotelian concept of eudaimonia). Therefore, to use a Ricoeurian parlance, we can define ethics here as a mode of thinking and feeling that exceeds the limits of 
individual interests to embrace the responsiveness towards the other than itself (Ricoeur, 1992). The second draws on Foucault's conception of ethics as a process of 'self-fashioning' that concerns 'the kind of relationship you ought to have with yourself, rapport a soi ' (Foucault, 2000, p. 263). In this respect, ethics is a form of continual work on the self, a perennial activity of 'self bricolage' (Rabinow, 2000, p. xxxix). These two meanings of the term are closely interrelated for social entrepreneurs, insofar as they constitute their identity by engaging in a process of self-fashioning in relation to the objective of 'changing the world', and in the belief of acting for the good of others.

It must be noted that the simple fact that young and well-educated people want to 'change the world' is not actually new in itself. What characterises social entrepreneurs is the claim to effect this change by means of entrepreneurial tools. In this respect, in analogy with the freelancers discussed earlier, social entrepreneurs emerge as highly ambivalent subjects for they mark a difference in relation to both traditional forms of political subjectivation (i.e. those articulated in party politics and activism), and embody the individualistic ethos of the neoliberal subject par excellence, i.e. the entrepreneur of the self, who is by definition concerned only with her or his private interest and wealth (Bauman, 2002; McNay, 2009; Lazzarato, 2009; Donzelot, 1991). Yet, this ambivalence does not determine a 'fracture' as in the case of freelancers seen above - it is in fact a reconciliation. Social entrepreneurs bridge the gap between entrepreneurial individualism and ethical responsiveness by putting their virtues and values at work in a way that is entirely similar to the valorisation of talents and passions by creative and cultural workers (McRobbie 1998, 2002; Ross, 2004; Arvidsson et al., 2010; Arvidsson et al., 2016)

Social entrepreneurs, nonetheless, also act in, and contribute to, the attempt to establish an 'alternative' kind of economy that is collaborative and commonsbased in logic. Consistently, they promote values of cooperation, collaboration and sharing often expressed and represented by the signifier 'community', a term widely used across the scene and particularly so at Impact Hub. For instance, at Impact Hub Westminster, this signifier is also physically distributed throughout the space - a sign giving instruction on how to use the kitchen facilities reads 'Welcome to the Community Kitchen!'; a glass house used for meetings is decorated with big capital letters claiming 'This is Community'; on leaving the space users are reminded that 'Together We Make Community'. As in most co-working environments, the community is here not to be understood in its traditional sociological significance, rather as a discursive translation of the 'open source approach to work' intended to facilitate collaborative practice that ultimately seeks to establish social relations among the member-workers (Gandini, 2015). Despite not being a social group bounded by a common background and narrative, there is still evidence of the need to establish social relations in the context of a collaborative approach to work.

Yet, social entrepreneurs also enact a form of collaborative economy and sociality beyond the co-working space's walls. They organise and participate in workshops, conferences, and - more generally - events (e.g. pop-up think 
tanks, innovation camps, business clinics, etc.) whose main purpose is the sharing of knowledge, skills, experiences and contacts. In this regard, the social entrepreneurial subjectivity is surely oriented towards practices of collaboration and sharing. Yet, their modes and objectives may reveal, again, an ambivalent character.

On the one hand, social entrepreneurs' discourses and practices imply and, to an extent, demand the creation of human relationships alongside the display of ethical values and virtues. This combination of social relationships and ethical values is due to the fact that one of the requirements to establish relationships in the scene is exactly to display and prove the will to have a 'positive impact' in other words, to be a changemaker (or, at the very least, a changemaker wannabe), therefore to show a virtuous character. The barriers of inclusion and exclusion from the scene revolve around the embodiment of a number of ethical principles that are thought to characterise and distinguish social entrepreneurial subjects (Bandinelli and Arvidsson, 2013).

On the other hand, the very embodiment and display of such ethical virtues, and the related engagements in collaborative relations, is ultimately instrumental to the acquisition of the necessary capital (social, cultural and economic) to further one's career. Virtually every social entrepreneur observed made clear that establishing friendships, and collaborating on projects, even with no immediate financial reward, was part of a strategy to eventually 'find a paid job'. It could thus be argued that, for these subjects, collaboration and ethics assume a somewhat opportunistic character. According to Paolo Virno (2005), opportunists are those whose socialisation is characterised by 'a flow of ever-interchangeable possibilities, making themselves available to the greatest number of these, yielding to the nearest one and then quickly swerving from one to another' (p. 86). To be an opportunist, Virno continues, is a professional quality, a skill which is acquired in a mode of socialisation that is increasingly connected with work (Virno, 2005, p. 86). Far from pretending to solve the inherent contradiction between individualism and social responsibility, collaboration and opportunism, it may be argued that social entrepreneurs are exemplary of a subjectivity that combines individualism and entrepreneurialism with the political will to 'change the world', and with the articulation of values and virtues that exceed the boundaries of private wealth and interest. Whilst their economic positioning puts them in coherence with the forms of subjectification that characterise freelancers, as illustrated above, the more social nuance of their subjectivity aligns them with the political intent towards change that characterises artists, who are the focus of the analysis in the next section.

\section{The radical subjectivity of artists}

The reflections offered here on the subjectivity of artist and cultural workers originate from research on Macao, the 'New Center for Arts, Culture and 
Research' in Milan, conducted by one of the authors in 2012-2013 during an 18-month ethnography comprising of 35 semi-structured interviews, surveys and digital methods (see Cossu, 2015). Active since 2012, Macao started as a project led by artists and curators that aimed at raising awareness on the conditions of cultural workers, and quickly spread through the social fabric of Milan, the Italian city with the highest density of this kind of workforce (Arvidsson et al., 2010; Bonomi, 2008). The project originated from the occupation of an abandoned 33-storey building in the heart of the financial district of Milan, which gathered thousands of people to reclaim the skyscraper for the city. Macao can be viewed as many things: a hub, a brand, a space, a process, a group of activists, a venue for concerts, a number of rooms bookable for free for seminars or exhibitions, an alternative innovation centre, a partner of EU-funded projects, or an illegal squat. To pin down its unique artistic voice it is necessary to contextualise Macao within a broader - and renewed - wave of art activism. In the words of Boris Groys:

Current discussions about art are very much centered on the question of art activism, that is, on the ability of art to function as an arena and medium for political protest and social activism. The phenomenon of art activism is central to our time because it is a new phenomenon quite different from the phenomenon of critical art that became familiar to us during recent decades. Art activists do not want to merely criticize the art system or the general political and social conditions under which this system functions. Rather, they want to change these conditions by means of art - not so much inside the art system but outside it, in reality itself. (Groys, 2014, p. 1)

Concerning Macao's composition, their rank-and-file participants are highly engaged with this endeavour and represent many subjects at the same time. According to a self-inquiry conducted by Macao on its base in winter 2012 (Macao, 2012) participants in the mobilization were 'working' for Macao a staggering 35 hours a week on average, on top of their day jobs - many of these on a freelance basis. To provide a snapshot, the average Macao activist is in her mid-thirties, highly skilled, usually with a degree and more than one job, and is both dissatisfied with her income and work life. Data also reveal that the top third of Macao's participants are relatively well off, earning $€ 2,000 /$ month on average, whilst the bottom third is under the relative poverty threshold. This means that whereas the top tier is able to afford a relatively decorous life and pay the rent of a non-shared house - owning a house, in some cases - thanks to high-added-value collaborations, freelancing and publicly-funded projects (outside Macao), on the contrary those in the lower tier often live with their families and report unsuccessful careers in the creative industry.

This brief breakdown evidences some of the complexities inherent to a body of subjects whose subjectivity is shaped around the deploying of events. Events 
for Macao are a means to communicate the unexpected, through a carefully planned artistic performance. At the same time, the event may also be seen as an attempt to tune in with the language spoken by the city itself, Milan (Cossu and Murru, 2015), in which societal functioning is largely articulated through a grammar of events, from the most informal ones (the Aperitivo or happy hour) to the largest imaginable (the Expo). The economy of a city like Milan is itself deeply entrenched with social events, and oddly enough, the sustainment of the illegal occupation of Macao is based on a number of events that attract publics of consumers. Macao events vary considerably in qualitative terms, from hosting experimental and avant-garde forms of art (e.g. poetry readings), to organising music gigs (e.g. a concert of a famous Italian folk singer) or cultural events (e.g. a talk by software freedom activist Richard Stallman) that are capable of gathering large crowds. Their own political action, since its inception, is at risk of being subsumed by capitalist logics as of the potential gentrification of the working class area they currently inhabit; yet, the urban administration felt even more compelled to tackle the issue of abandoned spaces in Milan after their action, and has since promoted a top-down urban regeneration program. However, revealing of their political stance is the widespread awareness of being already subsumed, and the recognition of the inability of their action to solve the contradictions of capitalism well before this took place. A lively debate on the economy of Macao has been present since its start. Currently, a partnership with the EU-funded project D-CENT is engaged with the experimentation of a cryptocurrency (CommonCoin) that might offer a basic income and forms of exchange based on communities' own (political) values.

Macao directly organises, co-organises or hosts hundreds of events, often in partnership with other subjects - institutions, associations, or single individuals or directed and managed entirely by 'external' actors. This demonstrates the know-how possessed by Macao activists in terms of event organisation and the need for such a space in Milan. For instance, out of a total of 270 events in 2013, around 60 per cent were produced by Macao itself, while 40 per cent were co-organised with external actors. In addition, the public is involved at different levels in these events, as a traditional audience or with greater involvement as participants in workshops, up to the co-creation of performances. In the case of an event organised by external actors, Macao often acts as curator, with a particular attention to guarantee not just the mere artistic quality of the artwork, but also the quality of the process.

Alongside a strategy for economic sustainability based on the organisation of a diverse range of events, Macao is characterised by an emphasis on the relations implied in the artistic production process. In the business world, relations are often framed within a notion of 'organisation'. However, in the case of Macao the notions of 'organisation' and 'relation' actually refer to different schemes and political sensibilities. Whereas the notion of organizing entails a structured and structuring activity aimed at efficacy and goal-attainment, the notion of relation constitutes a looser and wider concept that embraces both 
general human relations and the abstract ideas that shape groups and communities together. In this sense, relations are intended in Macao as sites of political investment that are not leveraged to maximise an individual's reputation - as is the case, for instance, with freelancers. Rather, they are conceived as forms of struggle to redefine relations themselves and, ultimately, the search for a different (and better) life, in analogy with the notion of change brought forward by social entrepreneurs.

However, to capture the specificity of Macao's political action as well as the radical posture embodied by the subjectivity of its members as political innovators, we need to consider the political role they play in the dialectical relationship between the economic and the social. If activists have traditionally used their own political subjectification to resist being corrupted by capitalism, and social innovators (such as the social entrepreneurs discussed above) are using capitalist tools to some extent against it, and in the absence of an explicit political subjectivity, then we could interpret Macao as a case of militant imagination striving to combine the two - thanks to the enactment of a political attitude and its application to and through cultural and social innovation.

Put differently, what we are confronted with in this case are subjects whose idea of change, that is deeply at the heart of the subjectivity and the collective recognition of Macao itself as an entity, is empirically based on 'making together' (Sennett, 2013) and strongly anchored to the belief that social relations precede and even supercede production - an idea that, despite inherent differences, has much in common with the ethos of social entrepreneurs. Similar to the sort of 'post-political' subjectivity inherent in the notion of change advocated by social entrepreneurs, the notion of change that characterises Macao and the subjects participating in it consists of an attempt to move beyond the dialectical relationship between the economic and the social, towards a more collective direction. As subjects who have always felt uneasy identifying themselves in initiatives deemed to be too 'political' and potentially identitarian, artists are seemingly witnessing a political turn in a yet to be defined post-ideological field that shares traits with the social entrepreneurial attempt to marry profit with social good.

\section{Discussion and conclusion}

This chapter has offered a discussion of the subjectivity of freelancers, social entrepreneurs and artists using an original weaving of three different empirical ethnographic research projects. Despite peculiar differences in research design, the juxtaposition of these 'thick descriptions' offers an otherwise unavailable variety of insights which provides existing research on the creative economy with a better sense of how the bigger picture of creative work and the creative economy as a whole might look like in the unfolding of what should be seen as a 'collaborative turn' in the economy and in society. To begin with, it may be 
argued that these subjects seem to share a kind of subjectivity that is underpinned by ambivalent notions of newness and change. This is realised through an analogous tension with/within the social that re-articulates processes of collectivisation in different ways. Their rising relevance as protagonists in the current scenario comes along with, and to some extent as a consequence of, the experience of processes of political subjectification that are based on stronger (artists), more ephemeral (social entrepreneurs) or comprehensively fragmented (freelancers) collective self-perceptions. The new element here is the attempt to try and combine the economic with what we can describe as a sort of 'aest-ethical' action with the aim to find themselves in an 'other' space where the social is put to work and re-embedded in the economic.

This comes about in three distinct ways that span across varying degrees of reflexivity and critique. Freelancers, for instance, put to work their social relations in an explicitly market-based logic, with a degree of critical interiorisation that varies consistently among them. Social entrepreneurs, on the other hand, put to work their 'ethical' virtues with the aim of a somewhat vague notion of the common good, seeing themselves as a kind of social movement that finds its roots in the same economic-oriented milieu that entrepreneurial freelancers populate - in fact some of them are, as discussed, professional freelancers in the creative industries. Finally, artists more explicitly articulate this subjectification in a collectivised approach that nonetheless struggles to become a comprehensive body. This vision represents an ideal progression from fragmentation to coalition, and in spite of internal fragmentation openly aims at being a social movement that might overcome the argued dialectical relationship by means of togetherness.

Taken as a whole, the study of the subjectivity of these peculiar social actors indicates that these subjects are intervening onto the social fabric in the postcrisis creative economy by enacting different forms of 're-embeddedness' of the economic into the social - with varying degrees of collaboration, redistribution and reciprocity. The social logic of action that characterises freelancers, social entrepreneurs and artists locates these subjects at the crossroads of the economic and the social, as social actors that tend towards the development of proto-collective forms of consciousness but still fluctuate between forms of cooperativism that might foster solidarity and the individualised nature of neoliberal subsumption. Their action inhabits a hybrid socio-economic space whereby their personal stories, their cultural, social and economic capital come together in the form of a shared ethos they are ultimately unable to recognise as such, as with the ambivalent blend of collaboration with (self-) entrepreneurship. These processes are activated in response to the relative employment challenges they face, and the difficulty in getting collective representation in the more complex political arena.

The space we wanted to map by taking these subjects together is one that is created via practices that are by no means new - freelance work, social entrepreneurship and artist-based social movements were there, in various ways, well before contemporary ideas of 'collaborative' forms of production were 
fashionable. Yet, what is new in this picture is that such practices, contoured by a discursive framework that legitimises economic action as an eminently social endeavour, seems to determine forms of 'integration' between the economy and society (Pais and Provasi, 2015) that are characterised by a re-embeddedness of the economy within eminently societal relations of production. Still, this is a contradictory mix that on the one hand revises processes of collectivisation typical of social movements in the absence of adequate political and trade union representation, and on the other hand operates a misleading rebranding of economic action through a new lexicon. Moreover, the social actors discussed in this chapter illustrate the existence of an organisational form that is not merely networked, i.e. principled on social relations, but actually built on the social relation itself. We believe the acknowledgment of these actors as central, and the understanding of their contradictory positioning in the bigger picture of an emerging economy based on collaboration, is the necessary step to found a political economy of creative work that moves beyond the - still necessary - critique of exploitation and precariousness and develops an intellectual and critical approach that is capable of not only making sense of the existing criticalities, but also dismantling its discursive rhetoric.

\section{References}

Arvidsson, A., Gandini, A., and Bandinelli, C. (2016). The ethics of self-branding among freelance knowledge workers. In Crain, M., Poster, W., \& Cherry, M.A. (Eds.), Invisible Labour: Hidden Work in the Contemporary World, Oakland, CA: University of California Press, pp. 239-56.

Arvidsson, A. and Peitersen, N. (2013). The Ethical Economy: Rebuilding Value After the Crisis. New York: Columbia University Press.

Arvidsson, A., Serpica, N., Malossi, G. (2010). Passionate work? Labour conditions in the Milan fashion industry. Journal for Cultural Research, 14(3): 259-309.

Bandinelli, C. (2016). Social entrepreneurship: Sociality, ethics and politics. Unpublished PhD dissertation, $\mathrm{PhD}$ in Cultural Studies, Goldsmiths College, University of London.

Bandinelli, C. and Arvidsson, A. (2013). Brand yourself a changemaker! Journal of Macromarketing, 33 (1): 67-71.

Banks et al. Eds. (2014) Theorizing Cultural Work: Labour, Continuity and Change in the Cultural and Creative Industries. London: Routledge.

Barley, S. R., \& Kunda, G. (2006). Contracting: A new form of professional practice. The Academy of Management Perspectives, 20(1): 45-66.

Bauman, Z. (2002). Individually Together. Preface to U. Beck, and E. BeckGernsheim, Individualization: Institutionalized Individualism and its Social and Political Consequences, pp. xiv-xix. London \& Thousand Oaks: Sage. 
Blair, H. (2001). 'You're only as good as your last job': The labour process and labour market in the British film industry, Work, Employment \& Society, 15(1): 149-69.

Bonini, T. \& Gandini, A. (2016). Invisible, solidary, unbranded and passionate. Everyday life as a freelance and precarious worker in four Italian radio stations. Work Organisation, Labour and Globalisation, 10 (2): 84-100.

Bonomi, A. (2008). Milano ai tempi delle moltitudini. Milano: Bruno Mondadori. Bourdieu, P. (1996). The Rules of Art: Genesis and Structure of the Literary Field, translated from French by S. Emanuel. Cambridge: Polity Press.

Botsman, R., and Rogers, R. (2010). What's Mine is Yours: The Rise of Collaborative Consumption. New York: HarperCollins.

Christopherson, S. (2008). Beyond the self-expressive creative worker:An industry perspective on entertainment media. Theory, Culture \& Society, 25(7-8): 73-95.

Cossu, A. (2015) Mobilizing art. An inquiry on the role of art in social movements: The case of Macao. Unpublished PhD dissertation, $\mathrm{PhD}$ in Sociology, University of Milan.

- (2015). Mobilising Art: An inquiry into the role of art in social movements: The case of Macao - Milano. Unpublished PhD Dissertation, University of Milan, Graduate School in Social and Political Sciences.

Cossu, A. \& Murru, M.F. (2015). Macao prima e oltre i Social Media: la creazione dell'inatteso come logica di mobilitazione, Studi Culturali 3: 353-372, DOI: https://doi.org/ 10.1405/81912 (English Trans. Macao before and beyond Social Media: The creation of the unexpected as a logic of mobilization).

Creative Skillset. (2015). Workforce survey calls for fairer access to creative media industries. Retrieved from: http://creativeskillset.org/news_events/ press_office/3412_workforce_survey_calls_for_fairer_access_to_creative_ media_industries.

DCMS. (2015). Creative Industries: Focus on Employment. Department for Culture, Media and Sport, UK, London. Retrieved from: https://www.gov. uk/government/uploads/system/uploads/attachment_data/file/439714/ Annex_C_-_Creative_Industries_Focus_on_Employment_2015.pdf.

DCMS. (2001). 'Creative Industries Mapping Document'. Department of Culture, Media and Sport, UK, London. Retrieved from: https://www.gov.uk/ government/publications/creative-industries-mapping-documents- 2001 .

DCMS. (1998). Creative Industries Mapping Document. Department of Culture, Media and Sport, UK, London. Retrieved from https://www.gov.uk/govern ment/publications/creative-industries-mapping-documents-1998.

de Peuter, G. (2014). Beyond the model worker: Surveying a creative precariat. Culture Unbound: Journal of Current Cultural Research 6 pp. 263-284.

Donzelot, J. (1991). Pleasure in Work, in G. Burchell, C. Gordon \& P. Miller (Eds.), The Foucault Effect: Studies in Governmentality. Chicago IL, University of Chicago Press, pp. 251-80. 
Economist, The. (2015). Workers on tap. Retrieved from: http://www.economist.com/news/leaders/21637393-rise-demand-economy-poses-difficult$\neg$ questions-workers-companies-and.

Faccioli, F., Gallina, M., Iaione, C., Leon, A. and Melotti, M. (2014). Rapporto sul futuro del Teatro Valle. Retrieved from: http//www.academia. edu/7825873/Rapporto_sul_Futuro_del_Teatro_Valle.

Florida, R. (2002). The Rise of the Creative Class. New York: Basic Books.

Foucault, M. (1994). Ethics, Subjectivity and Truth. New York: New Press.

-. (2000) Ethics. Essential Works 1954-1984, Vol. 1. London: Penguin

. (2008) The Birth of Biopolitics. Lectures at the College de France 19781979. Basingstoke: Palgrave Macmillan.

Gandini, A. (2015). The rise of coworking spaces: A literature review, Ephemera, 15(1): 193-205.

Gandini, A. (2016a). Digital work: Self-branding and social capital in the freelance knowledge economy, Marketing Theory, 16(1): 123-41

- (2016b). The Reputation Economy. Understanding Knowledge Work in Digital Society. Basingstoke: Palgrave Macmillan.

Goos, M., \& Manning, A. (2007). Lousy and lovely jobs: The rising polarization of work in Britain, The Review of Economics and Statistics, 89(1): 118-33.

Groys, B. (2014). On Art Activism, E-Flux, 1/2014. Retrieved from: http:// www.e-flux.com/journal/on-art-activism.

Hesmondhalgh, D. and Baker, S. (2011). Creative Labour: Media Work in Three Cultural Industries. London: Routledge.

Kalleberg, A. (2011) Good Jobs. Bad Jobs: The Rise of Polarized and Precarious Employment Systems in the United States, 1970s to 2000s. New York: Russell Sage Foundation.

Landry, C. (2000). The Creative City: A Toolkit for Urban Innovators. London: Earthscan.

Lazzarato, M. (1997) Lavoro immateriale: Forme di vita e produzione di soggettività. Verona, Italy: Ombre Corte.

Lazzarato, M. (2009). Neoliberalism in action: Inequality, insecurity and the reconstitution of the social. Theory, Culture \& Society, 26(6): 109-33.

Macao. (2012). 69300 ore. La produzione artistica e culturale nella città fabbrica: sistemi di cattura e pratiche di lotta. Retrieved from https://issuu.com/ macaomilano/docs/69300_ore.

Malone, T.W. and Laubacher, R.J. The dawn of the e-lance economy. Harvard Business Review 1998, 76(5):144-52

McKinlay, A., \& Smith, C. (eds). (2009). Creative Labour: Working in the Creative Industries. Basingstoke: Palgrave Macmillan.

McNay, L. (2009). Self as enterprise: Dilemmas of control and resistance in Foucault's The Birth of Biopolitics, Theory, Culture \& Society, 26(6): $55-77$.

McRobbie, A. (1998). British Fashion Design: Rag Trade or Image Industry? London, New York: Routledge. 
. (2002). Clubs to companies: Notes on the decline of political culture in speeded up creative worlds. Cultural Studies, 16(4): 518-31.

- (2015). Be Creative: Making a Living in the New Culture Industries. London: Wiley.

Neilson, B., \& Coté, M. (2014). Introduction: Are we all cultural workers now? Journal of Cultural Economy, 7(1): 2-11.

Neilson, B., \& Rossiter, N. (2008). Precarity as a political concept, or, Fordism as exception. Theory, Culture \& Society, 25(7-8): 51-72.

Pais, I., \& Provasi, G. (2015). Sharing Economy: A step towards the reembeddedness of the economy? Stato e mercato, 105: 347-78.

Patel, K. (2017). Expertise and collaboration: Cultural workers' performance on social media. In J. Graham, A. Gandini (Eds.), Collaborative Production in the Creative Industries, London: University of Westminster Press.

Polanyi, K. [1944] (2001). The Great Transformation: The Political And Economic Origins Of Our Time. Beacon Press.

Prospects. (2015). Overview of the creative arts sector in the UK. Retrieved from http://www.prospects.ac.uk/creative_arts_design_sector_overview.htm.

Rabinow, P. (2000). The History of Systems of Thought, in Foucault, M. Ethics. Essential Works 1954-1984, Vol. 1. London: Penguin

Ricoeur, P. (1992). Oneself as Another. Chicago and London: University of Chicago Press.

Ross, A. (2004). No-Collar: The Humane Workplace and its Hidden Costs. Philadelphia, PN: Temple University Press.

- (2009). Nice Work If You Can Get It: Life and Labor in Precarious Times. New York: New York University Press.

Sennett, R. (2013). Together: The Rituals, Pleasures and Politics of Cooperation. New Haven, CT: Yale University Press.

Sholette, G. (2011). Dark Matter: Art and Politics in the Age of Enterprise Culture. London: Pluto Press.

Social Enterprise UK. (2013). The People's Business: State of Social Enterprise Survey 2013. Retrieved from: http://www.socialenterprise.org.uk/uploads/ files/2013/07/the_peoples_business.pdf.

Virno, P. (2003). A Grammar of the Multitude. Los Angeles, CA: Semiotext(e). Williamson, O. (1973). Markets and hierarchies: Some elementary considerations. American Economic Review 63(2): 316-25 